Article

\title{
Particularities of Older Patients with Obstructive Sleep Apnea and Heart Failure with Mid-Range Ejection Fraction
}

\author{
Carmen Loredana Ardelean $1, * \mathbb{0}$, Sorin Pescariu ${ }^{2}$, Daniel Florin Lighezan ${ }^{2}$, Roxana Pleava ${ }^{1, *}$, \\ Sorin Ursoniu ${ }^{3}(\mathbb{D})$, Valentin Nadasan ${ }^{4}$ and Stefan Mihaicuta ${ }^{5}$ (D) \\ 1 University of Medicine and Pharmacy, Dr Victor Babes, Eftimie Murgu Square 2, 300041 Timisoara, Romania \\ 2 Cardiology Department, University of Medicine and Pharmacy, Dr Victor Babes, Eftimie Murgu Square 2, \\ 300041 Timisoara, Romania \\ 3 Department of Public Health and Health Management, University of Medicine and Pharmacy, \\ Dr Victor Babes, Eftimie Murgu Square 2, 300041 Timisoara, Romania \\ 4 Department of Hygiene and Environmental Health, University of Medicine and Pharmacy, Sciences and \\ Technology of Targu Mures, Gheorghe Marinescu 38, 540139 Targu Mures, Romania \\ 5 Pneumology Department, University of Medicine and Pharmacy, Dr Victor Babes, Eftimie Murgu Square 2, \\ 300041 Timisoara, Romania \\ * Correspondence: carmenardelean79@yahoo.com (C.L.A.); roxana.pleava@gmail.com (R.P.); \\ Tel.: +00-407-2410-5175 (C.L.A.); +407-6555-8929 (R.P.)
}

Received: 22 June 2019; Accepted: 5 August 2019; Published: 7 August 2019

\begin{abstract}
Background and objectives: Obstructive sleep apnea syndrome (OSAS) and heart failure (HF) are increasing in prevalence with a greater impact on the health system. The aim of this study was to assess the particularities of patients with OSAS and HF, focusing on the new class of HF with mid-range ejection fraction ( $\mathrm{HFmrEF}, \mathrm{EF}=40 \%-49 \%$ ), and comparing it with reduced $\mathrm{EF}$ ( $\mathrm{HFrEF}, \mathrm{EF}$ $<40 \%$ ) and preserved EF (HFpEF, $\mathrm{EF} \geq 50 \%$ ). Materials and Methods: A total of 143 patients with OSAS and HF were evaluated in three sleep labs of "Victor Babes" Hospital and Cardiovascular Institute, Timisoara, Western Romania. We collected socio-demographic data, anthropometric sleep-related measurements, symptoms through sleep questionnaires and comorbidity-related data. We performed blood tests, cardio-respiratory polygraphy and echocardiographic measurements. Patients were divided into three groups depending on ejection fraction. Results: Patients with HFmrEF were older $(p$ $=0.0358)$, with higher values of the highest systolic blood pressure $(\mathrm{mmHg})(p=0.0016)$, higher serum creatinine $(p=0.0013)$, a lower glomerular filtration rate $(p=0.0003)$, higher glycemic levels $(p=0.008)$ and a larger left atrial diameter $(p=0.0002)$. Regarding comorbidities, data were presented as percentage, HFrEF vs. HFmrEF vs. HFpEF. Higher prevalence of diabetes mellitus (52.9 vs. 72.7 vs. $40.2, p=0.006$ ), chronic kidney disease (17.6 vs. 57.6 vs. $21.5, p<0.001)$, tricuspid insufficiency $(76.5$ vs. 84.8 vs.59.1, $p=0.018$ ) and aortic insufficiency ( 35.3 vs. 42.4 vs. $20.4, p=0.038$ ) were observed in patients with HFmrEF, whereas chronic obstructive pulmonary disease(COPD) (52.9 vs. 24.2 vs.18.3, $p=0.009)$, coronary artery disease(CAD) (82.4 vs. 6.7 vs. $49.5, p=0.026)$, myocardial infarction ( 35.3 vs. 24.2 vs. $5.4, p<0.001$ ) and impaired parietal heart kinetics (70.6 vs. 68.8 vs. $15.2, p<0.001$ ) were more prevalent in patients with HFrEF. Conclusions: Patients with OSAS and HF with mid-range EF may represent a new group with increased risk of developing life-long chronic kidney disease, diabetes mellitus, tricuspid and aortic insufficiency. COPD, myocardial infarction, impaired parietal kinetics and CAD are most prevalent comorbidities in HFrEF patients but they are closer in prevalence to HFmrEF than HFpEF.
\end{abstract}

Keywords: obstructive apnea; heart failure; risk factors; elderly; comorbidities 


\section{Introduction}

In recent years, obstructive sleep apnea syndrome (OSAS) has increased in prevalence, occurring in up to $10 \%$ of healthy subjects, due to the greater frequency of obesity and the aging of the population. Consequently, this has had an increasingly important impact on the health system [1]. The prevalence of OSAS in subjects with cardiovascular disease, reported in earlier studies, was between $50 \%$ and $80 \%$ [2-4], and in half of subjects with heart failure (HF), it is associated with increased mortality [5] and worse prognosis [6].

OSAS is globally known as a major factor for the occurrence of cardiometabolic comorbidities due to intermittent hypoxia which leads to oxidative stress, endothelial dysfunction, increase of sympathetic activity and systemic inflammation [7]. Furthermore, activation of the sympathetic nervous system leads to activation of the renin-angiotensin-aldosterone system, which increases hydro-saline retention and thus the level of blood pressure [8]. However, hydro-saline retention due to heart failure can also play an important role in the pathogenesis of OSAS [9]. These data suggest that the relationship between HF and OSAS is not fully understood.

Large studies have demonstrated that OSAS prevalence is higher in patients with coronary artery disease (CAD), HF, resistant arterial hypertension associated with risk of stroke, and uncontrolled arrhythmias [10].

Patients with OSAS present a variety of symptoms that correlate with anthropometric measurements, smoking habits, sedentarism and association of comorbidities [1]. In recent years, new perspectives regarding clinical presentations of OSAS with description of different phenotypes and clusters have emerged [11-13].

Different structural or functional cardiac abnormalities can lead to occurrence of typical symptoms and signs of HF as defined by the European Society of Cardiology (ESC) guidelines, increased morbidity and mortality and higher costs for the health system [14]. HF is more common in elderly patients, especially those over 60 years [15].

The measurement of the left ventricle ejection fraction (LVEF) is used to define HF. Accordingly, HF is classified as HF with preserved LVEF, $\geq 50 \%$ (HFpEF) and HF with reduced LVEF, $<40 \%(\mathrm{HFrEF})$. Recently, the latest guidelines on the diagnosis and management of heart failure published by the European Society of Cardiology proposed a new class of HF patients with LVEF $=40 \%-49 \%$ called HF with mid-range EF (HFmrEF), in order to better differentiate HF patients from the point of view of etiology, developing mechanisms and response to treatment strategy $[16,17]$.

\section{Materials and Methods}

\subsection{Study Subjects}

We enrolled consecutive patients evaluated for OSAS at the "Victor Babes" Timisoara Hospital between 2014 and 2018 and for HF at the Timisoara Institute for Cardiovascular Diseases. Inclusion criteria were patients with age over 40 years, with a diagnosis of heart failure and OSAS who performed cardio-respiratory polygraphy, echocardiography and blood test evaluation. Patients with incomplete evaluation and those with no OSAS or with predominantly central sleep apnea (CSA) were excluded. This study was approved by the Ethical Committee of the University of Medicine and Pharmacy "Victor Babes" Timisoara as a subject for a PhD thesis (number 14728/15 NOV 2013). The clinics where the patient's evaluations were performed have an established agreement with the university through which all the data obtained from the patients may be used for research purposes. Informed consent was signed by all the patients.

Patients were initially evaluated through a standard datasheet with the following parameters: Age (years), gender (male/female), weight $(\mathrm{kg})$ and height $(\mathrm{cm})$, followed by measurement of body mass index (BMI = weight in $\mathrm{kg} /$ squared height in $\mathrm{m})$, neck and abdominal circumference $(\mathrm{cm})$, presence and duration of hypertension, maximum and current value of blood pressure, medication, reported apneas, snoring, sleepiness, Epworth Sleepiness Scale, SAS score (sleep apnea syndrome score), 
morning headache, restless sleep, nocturia, nocturnal awakenings, chronic obstructive pulmonary disease (COPD), diabetes, dyslipidemia, CAD, HF, arrhythmias, stroke, nasal septum deviation, polyposis, hypertrophic uvula and smoking status (pack $\times$ years). Since it is not routine practice in our cardio-respiratory unit, we did not collect data about physical activity.

For the sleep study we followed the European standards for diagnosis of OSAS [18].

Cardio-respiratory polygraphy recording was performed with Stardust Respironics and Porti. Several parameters were measured: The number of apnea (individually, central, obstructive and mixed) and hypopnea per hour of sleep and per night, the AHI (apnea-hypopnea index), the desaturation index, the mean saturation, the lowest saturation, and the longest desaturation period below $88 \%$ (seconds). Because we did not perform full night assisted polysomnography, data about sleep duration and duration of the lowest desaturation were not recorded. Approximately one-third of the patients enrolled in this study used CPAP (continuous positive airway pressure) due to the non-reimbursement of the cost of this therapy. Therefore, data related to the use of CPAP have not been included in this study.

The cardio-respiratory polygraphy recording was performed and scored manually as stated by American Academy of Sleep Medicine standards and European Sleep Research Society recommendations [19].

Laboratory tests were performed in Romanian Accreditation Association-RENAR certified medical laboratories, as follows: ESR (erythrocyte sedimentation rate) $(\mathrm{mm} / \mathrm{h})$, glucose $(\mathrm{mg} / \mathrm{dL})$, uric acid $(\mathrm{mg} / \mathrm{dL})$, creatinine $(\mathrm{mg} / \mathrm{dL})$, erythrocyte count $\left(\times 10^{6} / \mu \mathrm{L}\right)$, hemoglobin $(\mathrm{g} / \mathrm{dL})$, sodium $(\mathrm{mmol} / \mathrm{L})$, potassium (mmol/L) and lipid profile (total cholesterol, LDL (low-density lipoprotein)-cholesterol, HDL (high-density lipoprotein)-cholesterol, triglycerides, mg/dl). Glomerular filtration rate, (GFR, $\mathrm{mL} / \mathrm{min} / 1.73 \mathrm{~m}^{2}$ ) was calculated for each patient, using CKD-EPI (Chronic Kidney Disease Epidemiology Collaboration) formula [20]. Blood samples were collected early in the morning after fasting, and within 1-2 days of informed consent if signing took place at a different time of day.

Cardiological evaluation was performed, for all patients, at the Institute of Cardiovascular Diseases in Timisoara, using the same diagnostic algorithm and equipment. We used the modified Simpson's rule for echocardiographic measurement of EF [21], and HF was classified depending on the LVEF, HF with preserved ejection fraction, $\mathrm{LVEF} \geq 50 \%$ (HFpEF); HF with reduced ejection fraction, $\mathrm{LVEF}<40 \%$ (HFrEF); and HF with mid-range ejection fraction, $\mathrm{LVEF}=40 \%-49 \%$ (HFmrEF). We also recorded end-diastolic volume $(\mathrm{mL})$, end-systolic volume $(\mathrm{mL})$, left atrium surface $\left(\mathrm{cm}^{2}\right)$, left atrium diameter $(\mathrm{cm})$, right ventricle diameter $(\mathrm{cm})$, mitral $\mathrm{E}$ and $\mathrm{A}$ wave $(\mathrm{m} / \mathrm{s}), \mathrm{E} / \mathrm{A}$ ratio, pulmonary artery pression $(\mathrm{mm} \mathrm{Hg})$ and percentage of patients with impaired parietal heart kinetics. Although, the assessment of the left ventricular internal dimension, left ventricular posterior wall, interventricular septum thickness is performed in current practice and provides valuable information about the HF etiology, in this study they were not recorded because we enrolled patients with heart failure, regardless of the underlying cardiac disease. We studied patients regarding LVEF only, as the main cardiac marker.

The morphological aspect, area $(\mathrm{cm})$, degree of regurgitation and stenoses and transvalvular pressure gradients were determined for the mitral, aortic, tricuspid and pulmonary valves [22].

\subsection{Statistical Analysis}

Data are presented as proportions, medians and interquartile range (IQR) for variables with a skewed distribution. The differences in the characteristics of the subjects were evaluated after being divided into three groups, depending on the $\mathrm{EF}$ ( $\mathrm{EF}<40 \%$, $\mathrm{EF}=40 \%-49 \%$, $\mathrm{EF} \geq 50 \%$ ). We used the chi-squared test (two degrees of freedom) for comparison of categorical data between groups of patients. Continuous data were tested for normality using the Kolmogorov-Smirnov test. Data with non-normal distributions were compared using the Kruskal-Wallis test. The $p$ values for all hypothesis tests were two-sided, and the $p$ value was set to the statistical significance threshold of $<0.005$. All data analyses were performed with Stata 15.1 (Statacorp, TX, USA). 


\section{Results}

A total of 143 patients with OSAS and HF were evaluated in three sleep labs of Timisoara "Victor Babes" Hospital, Western Romania.

\subsection{Socio-Demographic and Anthropometric Data}

Patients were divided into three groups depending on EF, with the following characteristics, presented as median and interquartile range: 17 patients $(11.88 \%)$ with $\mathrm{HFrEF}$, of which 15 male (88\%), age 61 (56-69) years, BMI 35 (31-36) kg/m², neck circumference 44 (39-46) cm, abdominal circumference $120(114-128) \mathrm{cm} ; 33$ patients (23.07\%) with $\mathrm{HFmrEF}$, of which 22 male (67\%), age 64.5 (57.5-71) years, BMI $36(31.5-41.5) \mathrm{kg} / \mathrm{m}^{2}$, neck circumference 45 (42-46) cm, abdominal circumference 120 (114-130) cm; 93 patients (65.93\%) with HFpEF, of which 62 male (67\%), BMI $35(31-41) \mathrm{kg} / \mathrm{m}^{2}$, neck circumference $44(41-46) \mathrm{cm}$, abdominal circumference $122(115-130) \mathrm{cm}$ (Table 1).

Table 1. Socio-demographic and anthropometric data.

\begin{tabular}{|c|c|c|c|c|}
\hline General Data & $\begin{array}{c}\mathrm{EF}<40 \%(\mathrm{HFrEF}) \\
n=17\end{array}$ & $\begin{array}{c}\mathrm{EF}=40 \%-49 \%(\mathrm{HFmrEF}) \\
n=33\end{array}$ & $\begin{array}{c}\mathrm{EF} \geq 50 \%(\mathrm{HFpEF}) \\
n=93\end{array}$ & $p$-Value \\
\hline Age (years) & $61(56-69)$ & $64.5(57.5-71)$ & $61(56-67)$ & 0.0358 \\
\hline Male (n0., \%) & $15(88 \%)$ & $22(67 \%)$ & $62(67 \%)$ & 0.187 \\
\hline BMI $\left(\mathrm{kg} / \mathrm{m}^{2}\right)$ & $35(31-36)$ & $36(31.5-41.5)$ & $35(31-41)$ & 0.415 \\
\hline Neck circumference $(\mathrm{cm})$ & $44(39-46)$ & $45(42-46)$ & $44(41-46)$ & 0.6573 \\
\hline $\begin{array}{l}\text { Abdominal circumference } \\
\qquad(\mathrm{cm})\end{array}$ & $120(114-128)$ & $120(114-130)$ & $122(115-130)$ & 0.8569 \\
\hline
\end{tabular}

Data are presented as proportions, medians and interquartile range (IQR). EF, ejection fraction; HFrEF, heart failure with reduced ejection fraction; HFmrEF, heart failure with mid-range EF; HFpEF, heart failure with preserved EF; BMI, body mass index.

Patients from the HFmrEF group were significantly older. More males were found in the HFrEF group. There were no differences in terms of BMI, neck and abdominal circumference (Table 1).

\subsection{Sleep Study and Blood Pressure Data}

There were no differences between groups of patients regarding blood pressure (BP) measurement and sleep study, systolic and diastolic BP at visit, AHI, type of apneas, desaturation index, medium and lowest desaturation, longest desaturation $<88 \%$ and sleep questionnaire. Significant differences were observed in patients with HFmrEF regarding the highest systolic BP reported by the patients $(p=0.016)$ (Table 2).

Table 2. Blood pressure and sleep study.

\begin{tabular}{|c|c|c|c|c|}
\hline $\begin{array}{c}\text { Sleep/Blood Pressure } \\
\text { Parameters }\end{array}$ & $\begin{array}{c}\mathrm{EF}<40 \% \text { (HFrEF) } \\
n=17\end{array}$ & $\begin{array}{c}\mathrm{EF}=40 \%-49 \%(\mathrm{HFmrEF}) \\
n=33\end{array}$ & $\begin{array}{c}\mathrm{EF} \geq 50 \%(\mathrm{HFpEF}) \\
n=93\end{array}$ & $p$-Value \\
\hline Highest Systolic BP (mmHg) & $161(161-179)$ & $202(177.5-220)$ & $191(170-210)$ & 0.0016 \\
\hline Highest Diastolic BP (mmHg) & $90(80-100)$ & $100(90-110)$ & $100(90-110)$ & 0.1472 \\
\hline $\begin{array}{c}\text { Duration of hypertension } \\
\text { (years) }\end{array}$ & $12(7-20)$ & $10(8-14.5)$ & $10(5-15)$ & 0.3899 \\
\hline AHI (events/h) & $42(24-53)$ & $38(24-48.5)$ & $44(27-62)$ & 0.1633 \\
\hline Central apneas & $1(0.4-9.5)$ & $1.25(0.25-4.66$ & $1.7(0.3-5.4)$ & 0.8947 \\
\hline Obstructive apneas & $13.2(8.9-21.3)$ & $14.55(7.2-23.8)$ & $19.2(12-38.2)$ & 0.0704 \\
\hline Mixed apneas & $2(0.9-6)$ & $1.75(0.45-3.2)$ & $2.1(0.7-6.1)$ & 0.3153 \\
\hline Desaturation index & $24(14.5-51)$ & $30.5(13.4-46.4)$ & $39.5(19-53)$ & 0.1856 \\
\hline Medium SpO2 (\%) & $93(90-94)$ & $92.5(91-94)$ & $92(89-93)$ & 0.1403 \\
\hline Lowest SpO2 (\%) & $78(76-83)$ & $76(66-83)$ & $77(62-83)$ & 0.6183 \\
\hline $\begin{array}{c}\text { Longest duration } \mathrm{SpO} 2<88 \% \\
\text { (sec) }\end{array}$ & $50(21-115)$ & $61(27-110.5)$ & $83(30-139)$ & 0.3311 \\
\hline Epworth Sleepiness Scale & $13(12-17)$ & $12(9-15)$ & $13(10-18)$ & 0.0819 \\
\hline SAS score & $4.9(4.5-5.4)$ & $4.3(4.1-4.85)$ & $4.8(4.1-5.3)$ & 0.0857 \\
\hline
\end{tabular}

Data are presented as medians and interquartile range (IQR). BP, blood pressure; AHI, apnea-hypopnea index; $\mathrm{SpO} 2$, oxygen saturation; SAS score, sleep apneas syndrome score. 


\subsection{Blood Tests}

Routine blood tests revealed significant statistical difference in HFmrEF patients regarding level of glucose $(p=0.0081)$, creatinine $(p=0.0013)$ and GFR $(p=0.0003)$ (Table 3$)$. There were no differences for ESR, uric acid, erythrocytes, hemoglobin, $\mathrm{Na}, \mathrm{K}$, total cholesterol, LDL and HDL cholesterol, or triglycerides.

Table 3. Blood tests.

\begin{tabular}{|c|c|c|c|c|}
\hline Blood Tests & $\begin{array}{c}\mathrm{EF}<40 \% \text { (HFrEF) } \\
n=17\end{array}$ & $\begin{array}{c}\mathrm{EF}=40 \%-49 \%(\mathrm{HFmrEF}) \\
n=33\end{array}$ & $\begin{array}{c}\mathrm{EF} \geq 50 \%(\mathrm{HFpEF}) \\
n=93\end{array}$ & $p$-Value \\
\hline ESR (mm/h) & $10.5(8-25)$ & $15(8-32)$ & $12(6-25)$ & 0.4202 \\
\hline Glucose (mg/dL) & $122.5(104-130.5)$ & $126(107-180.5)$ & $108.5(94-127)$ & 0.0081 \\
\hline Uric acid (mg/dL) & $7(4.9-8.3)$ & $6.6(5.2-8.1)$ & $5.9(5-6.9)$ & 0.2547 \\
\hline Creatinine $(\mathrm{mg} / \mathrm{dL})$ & $1.15(0.98-1.3)$ & $1.33(1.13-1.6)$ & $1.075(0.9-1.33)$ & 0.0013 \\
\hline GFR $\left(\mathrm{mL} / \mathrm{min} / 1.73 \mathrm{~m}^{2}\right)$ & $61.8(58.9-78)$ & $48.8(38.7-61)$ & $65.7(51.3-82.3)$ & 0.0003 \\
\hline Erythrocytes $\left({ }^{*} 10^{6} / \mu \mathrm{L}\right)$ & $4.73(4.42-5.06)$ & $4.80(4.45-5.13)$ & $4.77(4.43-5.12)$ & 0.8399 \\
\hline Hemoglobin $(\mathrm{g} / \mathrm{dL})$ & $14.1(12-15.9)$ & $14(12.3-15.1)$ & $14.5(13.2-15.45)$ & 0.3972 \\
\hline $\mathrm{Na}+(\mathrm{mmol} / \mathrm{L})$ & $140(138.5-142)$ & $141(139-144)$ & $141(139-142)$ & 0.5287 \\
\hline $\mathrm{K}+(\mathrm{mmol} / \mathrm{L})$ & $4.13(4-4.65)$ & 4.35 (3.9-4.) & $4.2(4-4.6)$ & 0.8157 \\
\hline Cholesterol (mg/dL) & $166(143-182.5)$ & $163(130-195)$ & $164(135-205)$ & 0.9128 \\
\hline LDL cholesterol (mg/dL) & $123(87-132)$ & $94.5(84-117)$ & $98(69-132)$ & 0.9003 \\
\hline HDL cholesterol (mg/dL) & $45(36-48)$ & $45(32-54)$ & $43(37-52)$ & 0.7776 \\
\hline Triglycerides (mg/dL) & $128.5(90-166)$ & $96(82-151)$ & $125(92-193)$ & 0.3465 \\
\hline
\end{tabular}

Data are presented as medians and interquartile range (IQR). ESR, erythrocyte sedimentation rate; GFR, glomerular

Filtration Rate; LDL, low-density lipoprotein; HDL, high-density lipoprotein.

\subsection{Echocardiographic Measurements}

Regarding echocardiographic measurements, statistically significant differences were found for end-diastolic and end-systolic volumes, ejection fraction, and left atrial diameter. LA (left atrium) diameter was higher in patients with $\operatorname{HFmrEF}(p=0.0002)$, similar to other publications (Table 4)

Table 4. Echocardiographic measurements.

\begin{tabular}{|c|c|c|c|c|}
\hline $\begin{array}{c}\text { Echocardiography } \\
\text { Parameters }\end{array}$ & $\begin{array}{c}\mathrm{EF}<40 \%(\mathrm{HFrEF}) \\
n=17\end{array}$ & $\begin{array}{c}\mathrm{EF}=40 \%-49 \% \\
(\mathrm{HFmrEF}) \\
n=33\end{array}$ & $\begin{array}{c}\mathrm{EF} \geq 50 \% \text { (HFpEF) } \\
n=93\end{array}$ & $p$-Value \\
\hline End-diastolic volume (ml) & $185(140-220)$ & $118(94-155)$ & $130(110-147.5)$ & 0.0027 \\
\hline End-systolic volume (ml) & $123.5(90-154)$ & $64.9(53-84.5)$ & $60(48.5-65.5)$ & 0.0001 \\
\hline EF $(\%)$ & $31.58(30-35.71)$ & 44.87 (43.37-46.13) & $55(50.98-59)$ & 0.0001 \\
\hline LA surface $\left(\mathrm{cm}^{2}\right)$ & $27(21-32)$ & $28(24.5-31)$ & $25(23-29)$ & 0.4666 \\
\hline LA diameter $(\mathrm{cm})$ & $4.7(4.6-5)$ & $4.95(4.5-5.3)$ & $4.3(3.9-4.64)$ & 0.0002 \\
\hline RV diameter (cm) & $3.24(2.5-3.6)$ & $2.9(2.6-3.25)$ & $2.8(2.5-3.14)$ & 0.2684 \\
\hline Mitral E wave (m/s) & $0.74(0.63-1)$ & $0.76(0.58-1.07)$ & $0.73(0.55-0.9)$ & 0.298 \\
\hline Mitral A wave (m/s) & $0.70(0.5-1.07)$ & $0.8(0.6-1)$ & $0.7(0.6-0.9)$ & 0.6517 \\
\hline E/A ratio & $0.86(0.74-1.65)$ & $0.79(0.64-1.4)$ & $0.87(0.73-1.3)$ & 0.6883 \\
\hline PAP (mmHg) & $47.5(25-63.3)$ & $45(34.5-50)$ & $36(25.5-45.5)$ & 0.1303 \\
\hline
\end{tabular}

Data are presented as medians and interquartile range (IQR). LA, Left atrium; RV, right ventricle; PAP, pulmonary artery pressure.

\subsection{Comorbidities}

Regarding comorbidities, data were presented as proportions, HFrEF vs. HFmrEF vs. HFpEF. We observed that the group with HFmrEF has significantly more cases of diabetes mellitus (52.9 vs. 72.7 vs. $40.2 p=0.006)$, chronic kidney disease (17.6 vs. 57.6 vs. $21.5, p<0.001)$, valvular disease, tricuspid insufficiency ( 76.5 vs. 84.8 vs. $59.1, p=0.018$ ) and aortic insufficiency ( 35.3 vs. 42.4 vs. $20.4, p=0.038$ ). The group with HFrEF had more cases of COPD (52.9 vs. 24.2 vs. $18.3, p=0.009$ ), myocardial infarction ( 35.3 vs. 24.2 . vs $5.4, p<0.001)$, CAD ( 82.4 vs. 66.7 vs. $49.5, p=0.026$ ) and impaired heart parietal kinetics (70.6 vs. 68.8 vs. $15.2, p<0.001$ ). The presence of myocardial infarction, 
CAD and impaired heart parietal kinetics were much lower in HFpEF patients compared with HFmrEF and HFrEF (Table 5).

Table 5. Comorbidities.

\begin{tabular}{|c|c|c|c|c|}
\hline Comorbidities \% & $\begin{array}{c}\mathrm{EF}<40 \% \text { (HFrEF) } \\
n=17\end{array}$ & $\begin{array}{c}\mathrm{EF}=40 \%-49 \%(\mathrm{HFmrEF}) \\
n=33\end{array}$ & $\begin{array}{c}\mathrm{EF} \geq 50 \% \text { (HFpEF) } \\
n=93\end{array}$ & $p$-Value \\
\hline Hypertension & 100 & 97 & 95.7 & 0.670 \\
\hline Smoking & 35.3 & 15.2 & 36.6 & 0.070 \\
\hline COPD & 52.9 & 24.2 & 18.3 & 0.009 \\
\hline Diabetes mellitus & 52.9 & 72.7 & 40.2 & 0.006 \\
\hline Dyslipidemia & 76.5 & 66.7 & 66.7 & 0.719 \\
\hline Atrial fibrillation & 58.8 & 57.6 & 37.6 & 0.065 \\
\hline Stroke & 5.9 & 6.1 & 12.9 & 0.781 \\
\hline Myocardial infarction & 35.3 & 24.2 & 5.4 & $<0.001$ \\
\hline CAD & 82.4 & 66.7 & 49.5 & 0.026 \\
\hline CKD & 17.6 & 57.6 & 21.5 & $<0.001$ \\
\hline Mitral insufficiency & 94.1 & 90.9 & 77.4 & 0.088 \\
\hline Tricuspid insufficiency & 76.5 & 84.8 & 59.1 & 0.018 \\
\hline Aortic insufficiency & 35.3 & 42.4 & 20.4 & 0.038 \\
\hline Pulmonary insufficiency & 17.65 & 15.63 & 12.9 & 0.840 \\
\hline РАH & 47.1 & 39.4 & 25.8 & 0.298 \\
\hline $\begin{array}{c}\text { Pulmonary } \\
\text { thromboembolism }\end{array}$ & 5.9 & 3.0 & 5.4 & 0.863 \\
\hline $\begin{array}{l}\text { Impaired parietal heart } \\
\text { kinetics }\end{array}$ & 70.6 & 68.8 & 15.2 & $<0.001$ \\
\hline
\end{tabular}

COPD, chronic obstructive pulmonary disease; CAD, coronary artery disease; CDK, chronic kidney disease; PAH, pulmonary arterial hypertension.

\section{Discussion}

In our population, $23.07 \%$ of the patients had HFmrEF, higher than reports from recent studies where the percentage of the HFmrEF category is between $13 \%$ and $17 \%$ [23-26].

Men are more likely to have OSAS in patients with HF. Moreover, men have a higher incidence of HF in patients with OSAS [27]. In our study, patients with HFmrEF were older, with no significant differences regarding gender or neck and abdominal circumferences.

It is well known that obesity is an important risk factor for heart failure, and this association leads to multiple complications. In addition, obesity seems to be more prevalent in HF patients with preserved ejection fraction; this may occur due to poor echocardiographic images and error in LVEF measurement [28]. In our study, we included only patients with OSAS, and patients with HFmrEF were in stage 2 of obesity, with higher BMIs, but differences were not statistically significant. Central sleep apnea (CSA) is particularly noted in patients with $\mathrm{HFrEF}$, and decompensated HF has been recognized as a risk factor for CSA [29].

Some studies have demonstrated that patients with heart failure and OSAS are less symptomatic, regardless of AHI, and Epworth Sleepiness Scale does not correlate with AHI [30]. Questionnaires do not accurately predict OSAS in patients with cardio-vascular disease (CVD) [31]. Epworth Sleepiness Scale and SAS score can be beneficial in predicting OSAS, but in our groups of patients, although the values are high, differences between groups are insignificant [32].

In our group, all the patients have severe OSAS, regardless of EF. Patients with severe, untreated OSAS have a higher risk of fatal cardiovascular events, some studies show [33].

Our patients with HFmrEF have higher blood glucose, serum creatinine and decreased glomerular filtration rate.

Nielson demonstrated in a large study that patients with elevated blood glucose levels but without confirmed diabetes have an increased risk of developing HF. Therefore, these patients should be carefully monitored in order to prevent the onset of HF [34].

Many studies demonstrated that even mild impaired renal function, with transitory elevated level of serum creatinine, represents an important predictor for worsening of heart failure. 
The pathophysiology remains unclear, but venous congestion and intrabdominal pressure serve as a challenge for the development of new therapeutic approaches [35,36]. OSAS severity was correlated with elevated serum creatinine [37], while CKD stage 3 is considered a significant predictor of CSA, as was demonstrated by Fleischmann et al. [38].

In this study, lipid profile is not different as in a cohort with all severities of disease where OSAS severity was independently correlated with cholesterol and triglycerides levels, probably because all our patients have severe OSAS [39].

Often, patients with HFpEF present only increased wall thickness of the LV or the size of LA, which makes it even more difficult to diagnose. In our study, LA diameter was higher in patients with HFmrEF ( $p=0.0002)$, similar to other publications [40]. Moreover, the role of the left atrium in modulating LV function is well-known [41], and there are considerable amounts of data demonstrating that the size of the LA is directly proportional to the increased risk of cardiovascular events; this parameter is not used enough in clinical practice to determine the HF progression [42].

Wang et al. demonstrated in a recent meta-analysis that patients with moderate to severe tricuspid regurgitation (TR) have a higher risk of hospitalization for worsening HF and cardiac mortality. Patients with TR, regardless of severity, have a higher risk of all-cause mortality, compared with patients without tricuspid valvular disease [43]. Asymptomatic patients with HFpEF, but with severe aortic regurgitation (AR), have a higher risk of fatal cardiac events [44].

Comorbidities are very important in HF. Thus, comorbidity management plays a leading role in the treatment and progression of heart failure.

COPD is significantly more prevalent in HFrEF in our population. COPD and OSAS have common pathophysiological mechanisms, such as activation of sympathetic nervous system and inflammation, which can lead to increased cardiovascular risk. Furthermore, patients with association of these diseases, so called "overlap syndrome", are exposed to an even greater risk [7].

Some patients with advanced stages of COPD have right HF with peripheral edema and have increased likelihood of OSAS because of the shift of the rostral fluid from the legs during the night [45].

Chronic kidney disease is significantly more prevalent in the group of HFmrEF. Reports from ESADA (Sleep apnea network/European sleep apnea database) cohort study identify that in OSAS patients, decrease of GFR was predicted by baseline characteristics like older age, female gender, obese patients and severe nocturnal hypoxemia and by comorbidities like heart failure and arterial hypertension [46].

Several studies reported that HFmrEF patients have an increased risk of CAD as HFrEF patients, but all-cause mortality was similar to HFpEF [47,48]. The prognosis of HF, regardless of $\mathrm{EF}$, was correlated with common risk factors, such as age, underlying disease and comorbidities [49].

Chioncel et al. found that the long-term mortality rate in HFmrEF was between those patients with HFpEF and HFrEF [50], whereas Pascual-Figa et al. showed that HFmrEF patients match a clinical profile similar to HFrEF, with an increased risk of cardiovascular mortality, rather than HFpEF [51]. Still, there are contradictory data from other recent studies which showed that HFmrEF patients have a prognosis similar to HFpEF patients [52,53]. The results of treatment in the latest publication show increased controversies [54].

\section{Study Limitations}

This study has several limitations. The studied population is relatively small, and even smaller for the subjects with HFrEF. There are no data about sleep since we did not perform full-night assisted polysomnography. The results need to be confirmed by larger studies.

\section{Conclusions}

Patients with OSAS and HF with mid-range EF may represent a new group of patients with increased risk of developing life-long chronic kidney disease, diabetes mellitus, and tricuspid and aortic insufficiency. COPD, myocardial infarction, impaired heart parietal kinetics and CAD are the 
most prevalent comorbidities in HFrEF patients, but the prevalence of these is closer to that of HFmrEF than HFpEF. More studies are needed, on larger groups of patients, to determine how OSAS is involved in the progression of $\mathrm{HF}$, from borderline ejection fraction to more severe heart failure.

Author Contributions: Data curation, C.L.A., R.P., S.P., D.F.L., S.M.; formal analysis, S.U. and V.N.; methodology, C.L.A., S.P., D.F.L., S.M.; supervision, S.P., D.F.L., S.M.; writing-original draft, C.L.A., R.P., S.M.; writing一review and editing, C.L.A., S.P., S.M.

Funding: This research received no external funding.

Conflicts of Interest: The authors declare no conflict of interest.

\section{References}

1. Randerath, W.; Bassetti, C.L.; Bonsignore, M.R.; Farre, R.; Ferini-Strambi, L.; Grote, L.; Hedner, J.; Kohler, M.; Martinez-Garcia, M.A.; Mihaicuta, S.; et al. Challenges and perspectives in obstructive sleep apnea: Report by an ad hoc working group of the Sleep Disordered Breathing Group of the European Respiratory Society and the European Sleep Research Society. Eur. Respir. J. 2018, 52, 1702616. [CrossRef] [PubMed]

2. Yumino, D.; Wang, H.; Floras, J.S.; Newton, G.E.; Mak, S.; Ruttanaumpawan, P.; Parker, J.D.; Bradley, T.D. Prevalence and Physiological Predictors of Sleep Apnea in Patients With Heart Failure and Systolic Dysfunction. J. Card. Fail. 2009, 15, 279-285. [CrossRef] [PubMed]

3. Bassetti, C.L.; Milanova, M.; Gugger, M. Sleep-disordered breathing and acute ischemic stroke: Diagnosis, risk factors, treatment, evolution, and long-term clinical outcome. Stroke 2006, 37, 967-972. [CrossRef] [PubMed]

4. Logan, A.G.; Perlikowski, S.M.; Mente, A.; Tisler, A.; Tkacova, R.; Niroumand, M.; Leung, R.S.T.; Bradley, T.D. High prevalence of unrecognized sleep apnea in drug-resistant hypertension. J. Hypertens. 2001, 19, 2271-2277. [CrossRef] [PubMed]

5. Wang, H.; Parker, J.D.; Newton, G.E.; Floras, J.S.; Mak, S.; Chiu, K.-L.; Ruttanaumpawan, P.; Tomlinson, G.; Bradley, T.D. Influence of Obstructive Sleep Apnea on Mortality in Patients With Heart Failure. J. Am. Coll. Cardiol. 2007, 49, 1625-1631. [CrossRef] [PubMed]

6. Macdonald, M.; Fang, J.; Pittman, S.D.; White, D.P.; Malhotra, A. The Current Prevalence of Sleep Disordered Breathing in Congestive Heart Failure Patients Treated with Beta-Blockers. J. Clin. Sleep Med. 2008, 4, 38-42. [PubMed]

7. McNicholas, W.T.; Bonsignore, M.R. Sleep apnea as an independent risk factor for cardiovascular disease: Current evidence, basic mechanisms and research priorities. Eur. Respir. J. 2007, 29, 156-178. [CrossRef]

8. Bradley, T.D.; Floras, J.S. Sleep apnea and heart failure: Part I: Obstructive sleep apnea. Circulation 2003, 107, 1671-1678. [CrossRef]

9. Randerath, W.; Javaheri, S. Sleep-Disordered Breathing in Patients with Heart Failure. Curr. Sleep Med. Rep. 2016, 2, 99-106. [CrossRef]

10. Levy, P.; Kohler, M.; McNicholas, W.T.; Barbe, F.; McEvoy, R.D.; Somers, V.K.; Lavie, L.; Pepi, J.L. Obstructive sleep apnea syndrome. Nat. Rev. Dis. Primers 2015, 1, 15015. [CrossRef]

11. Mihaicuta, S.; Udrescu, M.; Topirceanu, A.; Udrescu, L. Network science meets respiratory medicine for OSAS phenotyping and severity prediction. PeerJ 2017, 5, e3289. [CrossRef]

12. Bonsignore, M.R.; Giron, M.C.S.; Marrone, O.; Castrogiovanni, A.; Montserrat, J.M. Personalised medicine in sleep respiratory disorders: Focus on obstructive sleep apnoea diagnosis and treatment. Eur. Respir. Rev. 2017, 26, 170069. [CrossRef]

13. Saaresranta, T.; Hedner, J.; Bonsignore, M.R.; Riha, R.L.; McNicholas, W.T.; Penzel, T.; Anttalainen, U.; Kvamme, J.A.; Pretl, M.; Sliwinski, P.; et al. Clinical Phenotypes and Comorbidity in European Sleep Apnoea Patients. PLoS ONE 2016, 11, e0163439. [CrossRef]

14. Van Riet, E.E.; Hoes, A.W.; Wagenaar, K.P.; Limburg, A.; Landman, M.A.; Rutten, F.H. Epidemiology of heart failure: The prevalence of heart failure and ventricular dysfunction in older adults over time. A systematic review. Eur. J. Heart Fail. 2016, 18, 242-252. [CrossRef]

15. Randerath, W.; Verbraecken, J.; Andreas, S.; Arzt, M.; Bloch, K.E.; Brack, T.; Buyse, B.; De Backer, W.; Eckert, D.J.; Grote, L.; et al. Definition, discrimination, diagnosis and treatment of central breathing disturbances during sleep. Eur. Respir. J. 2017, 49, 1600959. [CrossRef] 
16. Butler, J.; Fonarow, G.C.; Zile, M.R.; Lam, C.S.; Roessig, L.; Schelbert, E.B.; Shah, S.J.; Ahmed, A.; Bonow, R.O.; Cleland, J.G.; et al. Developing Therapies for Heart Failure with Preserved Ejection Fraction: Current State and Future Directions. JACC Hear. Fail. 2014, 2, 97-112. [CrossRef]

17. Ponikowski, P.; Voors, A.A.; Anker, S.D.; Bueno, H.; Cleland, J.G.F.; Coats, A.J.S.; Falk, V.; González-Juanatey, J.R.; Harjola, V.P.; Jankowska, E.A.; et al. ESC Scientific Document Group; 2016 ESC Guidelines for the diagnosis and treatment of acute and chronic heart failure: The Task Force for the diagnosis and treatment of acute and chronic heart failure of the European Society of Cardiology (ESC) Developed with the special contribution of the Heart Failure Association (HFA) of the ESC. Eur. Heart J. 2016, 37, 2129-2200.

18. Fischer, J.; Dogas, Z.; Bassetti, C.L.; Berg, S.; Grote, L.; Jennum, P.; Levy, P.; Mihaicuta, S.; Nobili, L.; Riemann, D.; et al. Standard procedures for adults in accredited sleep medicine centres in Europe. Executive Committee of the Assembly of the National Sleep Societies; Board of the European Sleep Research Society, Regensburg, Germany. J. Sleep Res. 2012, 21, 357-368. [CrossRef]

19. Grigg-Damberger, M.M. The AASM Scoring Manual four years later. J. Clin. Sleep Med. 2012, 8, 597-619. [CrossRef]

20. Levey, A.S.; Stevens, L.A.; Schmid, C.H.; Zhang, Y.L.; Castro, A.F., 3rd; Feldman, H.I.; Kusek, J.W.; Eggers, P.; Van Lente, F.; Greene, T.; et al. A new equation to estimate glomerular filtration rate. Ann. Intern Med. 2009, 150, 604-612. [CrossRef]

21. Rudski, L.G.; Lai, W.W.; Afilalo, J.; Hua, L.; Handschumacher, M.D.; Chandrasekaran, K.; Solomon, S.D.; Louie, E.K.; Schiller, N.B. Guidelines for the echocardiographic assessment of the right heart in adults: A report from the American Society of Echocardiography endorsed by the European Association of Echocardiography, a registered branch of the European Society of Cardiology, and the Canadian Society of Echocardiography. J. Am. Soc. Echocardiogr. 2010, 23, 685-713, quiz: 786-788.

22. Lancellotti, P.; Tribouilloy, C.; Hagendorff, A.; Moura, L.; Popescu, B.A.; Agricola, E.; Monin, J.-L.; Pierard, L.A.; Badano, L.; Zamorano, J.L.; et al. European Association of Echocardiography recommendations for the assessment of valvular regurgitation. Part 1: Aortic and pulmonary regurgitation (native valve disease). Eur. J. Echocardiogr. 2010, 11, 223-244. [CrossRef]

23. Cheng, R.K.; Cox, M.; Neely, M.L.; Heidenreich, P.A.; Bhatt, D.L.; Eapen, Z.J.; Hernandez, A.F.; Butler, J.; Yancy, C.W.; Fonarow, G.C. Outcomes in patients with heart failure with preserved, borderline, and reduced ejection fraction in the Medicare population. Am. Hear. J. 2014, 168, 721-730. [CrossRef]

24. Kapoor, J.R.; Kapoor, R.; Ju, C.; Heidenreich, P.A.; Eapen, Z.J.; Hernandez, A.F.; Butler, J.; Yancy, C.W.; Yancy, G.C. Precipitating clinical factors, heart failure characterization, and outcomes in patients hospitalized with heart failure with reduced, borderline, and preserved ejection fraction. JACC Heart Fail. 2016, 4, 464-472. [CrossRef]

25. Tsuji, K.; Sakata, Y.; Nochioka, K.; Miura, M.; Yamauchi, T.; Onose, T.; Abe, R.; Oikawa, T.; Kasahara, S.; Sato, M.; et al. Characterization of heart failure patients with mid-range left ventricular ejection fraction-a report from the CHART-2 Study. Eur. J. Hear. Fail. 2017, 19, 1258-1269. [CrossRef]

26. Coles, A.H.; Tisminetzky, M.; Yarzebski, J.; Lessard, D.; Gore, J.M.; Darling, C.E.; Goldberg, R.J. Magnitude of and Prognostic Factors Associated With 1-Year Mortality after Hospital Discharge for Acute Decompensated Heart Failure Based on Ejection Fraction Findings. J. Am. Heart Assoc. 2015, 4, e002303. [CrossRef]

27. Gottlieb, D.J.; Yenokyan, G.; Newman, A.B.; O’Connor, G.T.; Punjabi, N.M.; Quan, S.F.; Redline, S.; Resnick, H.E.; Tong, E.K.; Diener-West, M.; et al. A Prospective Study of Obstructive Sleep Apnea and Incident Coronary Heart Disease and Heart Failure: The Sleep Heart Health Study. Circulation 2010, 122, 352-360. [CrossRef]

28. Perk, J.; De Backer, G.; Gohlke, H.; Graham, I.; Reiner, Z.; Verschuren, M.; Albus, C.; Benlian, P.; Boysen, G.; Cifkova, R.; et al. European Guidelines on cardiovascular disease prevention in clinical practice (version 2012). The Fifth Joint Task Force of the European Society of Cardiology and Other Societies on Cardiovascular Disease Prevention in Clinical Practice. Eur. Heart J. 2012, 33, 1635-1701.

29. Yumino, D.; Kasai, T.; Kimmerly, D.; Amirthalingam, V.; Floras, J.S.; Bradley, T.D. Differing Effects of Obstructive and Central Sleep Apneas on Stroke Volume in Patients with Heart Failure. Am. J. Respir. Crit. Care Med. 2013, 187, 433-438. [CrossRef] 
30. Arzt, M.; Young, T.; Finn, L.; Skatrud, J.B.; Ryan, C.M.; Newton, G.E.; Mak, S.; Parker, J.D.; Floras, J.S.; Bradley, T.D. Sleepiness and sleep in patients with both systolic heart failure and obstructive sleep apnea. Arch. Intern. Med. 2006, 166, 1716-1722. [CrossRef]

31. Marin, J.M.; Carrizo, S.J.; Vicente, E.; Agusti, A.G. Long-term cardiovascular outcomes in men with obstructive sleep apnoea-hypopnoea with or without treatment with continuous positive airway pressure: An observational study. Lancet 2005, 365, 1046-1053. [CrossRef]

32. Reuter, H.; Herkenrath, S.; Treml, M.; Halbach, M.; Steven, D.; Frank, K.; Castrogiovanni, A.; Kietzmann, I.; Baldus, S.; Randerath, W.J. Sleep-disordered breathing in patients with cardiovascular diseases cannot be detected by ESS, STOP-BANG, and Berlin questionnaires. Clin. Res. Cardiol. 2018, 107, 1071-1078. [CrossRef]

33. Topîrceanu, A.; Udrescu, M.; Udrescu, L.; Ardelean, C.; Dan, R.; Reisz, D.; Mihaicuta, S. SAS score: Targeting high-specificity for efficient population-wide monitoring of obstructive sleep apnea. PLoS ONE 2018, 13, e0202042. [CrossRef]

34. Nielson, C.; Lange, T. Blood Glucose and Heart Failure in Nondiabetic Patients. Diabetes Care 2005, 28, 607-611. [CrossRef]

35. Udani, S.M.; Koyner, J.L. The Effects of Heart Failure on Renal Function. Cardiol. Clin. 2010, $28,453-465$. [CrossRef]

36. Marrone, O.; Bonsignore, M.R. Obstructive sleep apnea and chronic kidney disease: Open questions on a potential public health problem. J. Thorac. Dis. 2018, 10, 45-48. [CrossRef]

37. Agrawal, V.; Vanhecke, T.E.; Rai, B.; Franklin, B.A.; Sangal, R.B.; McCullough, P.A. Albuminuria and Renal Function in Obese Adults Evaluated for Obstructive Sleep Apnea. Nephron Clin. Pr. 2009, 113, c140-c147. [CrossRef]

38. Fleischmann, G.; Fillafer, G.; Matterer, H.; Skrabal, F.; Kotanko, P. Prevalence of chronic kidney disease in patients with suspected sleep apnea. Nephrol. Dial. Transplant. 2010, 25, 181-186. [CrossRef]

39. Gündüz, C.; Basoglu, O.K.; Hedner, J.; Zou, D.; Bonsignore, M.R.; Hein, H.; Staats, R.; Pataka, A.; Barbe, F.; Sliwinski, P.; et al. Obstructive sleep apnea independently predicts lipid levels: Data from the European Sleep Apnea Database. Respirology 2018, 23, 1180-1189. [CrossRef]

40. Holtstrand Hjälm, H.; Fu, M.; Hansson, P.O.; Zhong, Y.; Caidahl, K.; Mandalenakis, Z.; Morales, D.; Ergatoudes, C.; Rosengren, A.; Grote, L.; et al. Association between left atrial enlargement and obstructive sleep apnea in a general population of 71-year-old men. J. Sleep Res. 2018, 27, 252-258. [CrossRef]

41. Takemoto, Y.; Barnes, M.E.; Seward, J.B.; Lester, S.J.; Appleton, C.A.; Gersh, B.J.; Bailey, K.R.; Tsang, T.S. Usefulness of Left Atrial Volume in Predicting First Congestive Heart Failure in Patients $\geq 65$ Years of Age With Well-Preserved Left Ventricular Systolic Function. Am. J. Cardiol. 2005, 96, 832-836. [CrossRef]

42. Hoit, B.D. Left Atrial Size and Function: Role in Prognosis. J. Am. Coll. Cardiol. 2014, 63, 493-505. [CrossRef]

43. Wang, N.; Fulcher, J.; Abeysuriya, N.; McGrady, M.; Wilcox, I.; Celermajer, D.; Lal, S. Tricuspid regurgitation is associated with increased mortality independent of pulmonary pressures and right heart failure: A systematic review and meta-analysis. Eur. Heart J. 2018, 40, 476-484. [CrossRef]

44. Detaint, D.; Messika-Zeitoun, D.; Maalouf, J.; Tribouilloy, C.; Mahoney, D.W.; Tajik, A.J.; Enriquez-Sarano, M. Quantitative echocardiographic determinants of clinical outcome in asymptomatic patients with aortic regurgitation: A prospective study. JACC Cardiovasc. Imaging 2008, 1, 1-11. [CrossRef]

45. McNicholas, W.T. Comorbid obstructive sleep apnea and chronic obstructive pulmonary disease and the risk of cardiovascular disease. J. Thorac. Dis. 2018, 10, S4253-S4261. [CrossRef]

46. Marrone, O.; Battaglia, S.; Steiropoulos, P.; Basoglu, O.K.; Kvamme, J.A.; Ryan, S.; Pepin, J.L.; Verbraecken, J.; Grote, L.; Hedner, J.; et al. ESADA study group. Chronic kidney disease in European patients with obstructive sleep apnea: The ESADA cohort study. J. Sleep Res. 2016, 25, 739-745. [CrossRef]

47. Vedin, O.; Lam, C.S.; Koh, A.S.; Benson, L.; Teng, T.H.K.; Tay, W.T.; Braun, O.Ö.; Savarese, G.; Dahlström, U.; Lund, L.H. Significance of ischemic heart disease in patients with heart failure and preserved, midrange, and reduced ejection fraction: A nationwide cohort study. Circulation 2017, 10, e003875. [CrossRef]

48. Wang, N.; Hales, S.; Barin, E.; Tofler, G. Characteristics and outcome for heart failure patients with mid-range ejection fraction. J. Cardiovasc. Med. 2018, 19, 297-303. [CrossRef]

49. Lam, C.S.; Gamble, G.D.; Ling, L.H.; Sim, D.; Leong, K.T.G.; Yeo, P.S.D.; Ong, H.Y.; Jaufeerally, F.; Ng, T.P.; Cameron, V.A.; et al. Mortality associated with heart failure with preserved vs. reduced ejection fraction in a prospective international multi-ethnic cohort study. Eur. Heart J. 2018, 39, 1770-1780. [CrossRef] 
50. Chioncel, O.; Lainscak, M.; Seferovic, P.M.; Anker, S.D.; Crespo-Leiro, M.G.; Harjola, V.-P.; Parissis, J.; Laroche, C.; Piepoli, M.F.; Fonseca, C.; et al. Epidemiology and one-year outcomes in patients with chronic heart failure and preserved, mid-range and reduced ejection fraction: An analysis of the ESC Heart Failure Long-Term Registry. Eur. J. Hear. Fail. 2017, 19, 1574-1585. [CrossRef]

51. Pascual-Figal, D.A.; Ferrero-Gregori, A.; Gomez-Otero, I.; Vazquez, R.; Delgado-Jimenez, J.; Alvarez-Garcia, J.; Gimeno-Blanes, J.R.; Worner-Diz, F.; Bardají, A.; Alonso-Pulpon, L.; et al. MUSIC and REDINSCOR I research groups. Mid-range left ventricular ejection fraction: Clinical profile and cause of death in ambulatory patients with chronic heart failure. Int. J. Cardiol. 2017, 240, 265-270. [CrossRef] [PubMed]

52. Guisado-Espartero, M.E.; Salamanca-Bautista, P.; Aramburu-Bodas, Ó.; Conde-Martel, A.; Arias-Jiménez, J.L.; Llàcer-Iborra, P.; Dávila-Ramos, M.F.; Cabanes-Hernández, Y.; Manzano, L.; Montero-Pérez-Barquero, M.; et al. Heart failure with mid-range ejection fraction in patients admitted to internal medicine departments: Findings from the RICA registry. Int. J. Cardiol. 2018, 255, 124-128. [CrossRef] [PubMed]

53. Koh, A.S.; Tay, W.T.; Teng, T.H.K.; Vedin, O.; Benson, L.; Dahlström, U.; Savarese, G.; Lam, C.S.P.; Lund, L.H. A comprehensive population-based characterization of heart failure with mid-range ejection fraction. Eur. J. Heart Fail. 2017, 19, 1624-1634. [CrossRef] [PubMed]

54. McNicholas, W.T.; Bassetti, C.L.; Ferini-Strambi, L.; Pépin, J.L.; Pevernagie, D.; Verbraecken, J.; Randerath, W.; Baveno Working Group Members. Challenges in obstructive sleep apnoea. Lancet Respir. Med. 2018, 6, 170-172, Erratum in: Lancet Respir. Med. 2018, 6, e15. No abstract available. [CrossRef]

(C) 2019 by the authors. Licensee MDPI, Basel, Switzerland. This article is an open access article distributed under the terms and conditions of the Creative Commons Attribution (CC BY) license (http://creativecommons.org/licenses/by/4.0/). 